\title{
Advising Experiences of First-Year International Doctoral Students
}

\author{
Nina Marijanović \\ Jungmin Lee \\ Thomas W. Teague, Jr. \\ University of Kentucky, USA \\ Sheryl F. Means \\ University of New Mexico, USA
}

\begin{abstract}
The purpose of this qualitative study was to understand how international doctoral students were matched with their faculty advisors and how their advising experiences and satisfaction were shaped by their academic discipline. We applied the lens of developmental advising to situate the advising experiences of our sample because of the framework's emphasis on holistic support and student development. We conducted individual semistructured interviews with 21 international doctoral students attending a large research-intensive university in the Southeast. Most participants were assigned to an interim advisor, but the data revealed concerning differences in the type of advising experiences and support based on academic discipline. This study contributes to the body of literature by exploring advisor-advisee matching among international doctoral students and by further analyzing how disciplinary cultures shape perceptions of satisfaction with advising.
\end{abstract}

Keywords: advising experiences, advisor-advisee matching, doctoral students, faculty advisors, international students

The United States hosts a large share of international students, and it is among the top three global destinations for higher education studies (Zong \& Batalova, 
2018). While plentiful literature documents the types of experiences that hinder or encourage social and academic success and retention among this population, including difficulty in accessing campus support resources, campus and peer social networks, dedicated spaces for international students, and practicum and internship opportunities (Arthur, 2017; Chen et al., 2019; Heng, 2016), few studies specifically focus on international graduate students' experience with advisors (e.g., $\mathrm{Ng}$ et al., 2018; Zhao et al., 2007). To fill the gap, we sought to understand the advising experiences of first-year international doctoral students attending a large research-intensive university in the Southeast.

We sought to understand how international doctoral students were matched with their faculty advisors, what types of advising experiences they had, how these interactions differed by their academic discipline, and their level of satisfaction with their advising experience. We focused on advising experiences because faculty advisors are a cornerstone of students' social support networks, particularly for international doctoral students, who are often isolated from their primary support networks at home, and effective faculty advising can alleviate some of the transitional challenges faced by these students (Jeong et al., 2019). However, advising at the graduate level lacks standardization, and the diversity of advising styles leads to unequal doctoral advising experiences.

To assess the diversity of doctoral advising experiences, we applied the lens of developmental advising, which re-envisions the advising relationship as a shared give-and-take between the student and the advisor, rather than the advisor solely determining what the student needs. This advising model best captures the strengths and deficiencies experienced by our sample of international doctoral students. Our results can inform practitioners, particularly graduate faculty advisors and directors of graduate studies who are responsible for establishing and maintaining a healthy advising culture. Our results can also educate the wider international graduate student population on the importance of advising and how regular engagement with their advisor can increase academic, professional, and personal success.

\section{CONCEPTUAL FRAMEWORK}

Effective faculty advisors can increase academic self-concept and sense of belonging, particularly among international doctoral students who often enter graduate education without an established support system and with limited educational experiences with a North American style of higher education (Curtin et al., 2013; Omar et al., 2016). In this study, a graduate advisor refers to "a single faculty member the graduate student would consider in the primary, formal role of academic advisor, dissertation chair, or research supervisor" (Rice et al., 2009, p. 1). Furthermore, an international graduate student is "a student who moves to another country (the host country) for the purpose of pursuing tertiary or higher education (e.g., college or university)" (Shapiro et al., 2014, p. 2).

We chose the developmental advising model to situate the advising experiences of our sample because this model does not view the advisee as a passive participant in the advising relationship. While the advisor facilitates 
growth in the student's "rational processes, environmental and interpersonal interactions, behavioral awareness, problem-solving, decision-making, and evaluation skills," both parties experience different degrees of learning and growth because the relationship is meant to be reciprocal (Crookston, 1972, p. 5). Developmental advising is associated with increased retention, academic performance, satisfaction with degree selection, and overall advising experience, especially among women and minority students (Harris, 2018).

Developmental advising is more frequently applied and studied at the undergraduate level (McWilliams \& Beam, 2013). Nonetheless, graduate advisors should consider updating their advising approach considering graduate students' general dissatisfaction with advising (Kong et al., 2013; Wang \& Lorenz, 2018). High attrition rates among graduate students, including international graduate students, further erodes the attractiveness of graduate study and leads to lower institutional reputation and decreased funding. Implementing aspects of developmental advising at the graduate level could be one way to combat this issue.

\section{LITERATURE REVIEW}

A faculty advisor is an important agent of socialization for doctoral students, and daily interactions can significantly shape students' experiences and outcomes. A strong relationship with a faculty advisor can lead to timelier degree completion, more collaborative work with advisors, increased sense of belonging, and decreased stress and attrition (Hunter \& Devine, 2016; Litalien \& Guay, 2015). The faculty advisor can have many identities (Jeong et al., 2019; Zhao et al., 2007), but these identities are adopted from the faculty advisor's own experiences with advising, which are strongly influenced by their academic discipline and practices therein rather than formal training (Boyce et al., 2019; Knox et al., 2013). Insufficiency of formal training may explain why advisors often report being underprepared for the procedural and emotional factors that accompany advising (O'Meara et al., 2013). However, it is not just faculty advisors who are underprepared. Students also receive little training on how to engage with their faculty advisor, with many indicating mismatched expectations and lack of support as primary reasons for their dissatisfaction with advising (Wang \& Lorenz, 2018).

Mismatching and miscommunication may arise from the process by which students are matched with their advisor. In many doctoral programs, the responsibility of securing a faculty advisor and establishing an advising relationship is placed on the student rather than on the faculty advisor. This process assumes that all students have a shared understanding about the advising role and expectations therein; however, we know that that is not the case (Omar et al., 2016). Additionally, the timing of the match is important to consider as there are disciplinary differences in when students match with their advisor, with students in humanities and social science fields often matching with a permanent advisor later in their doctoral program, in comparison with students in biological 
and physical sciences fields who often match during the admission process (Zhao et al., 2007).

\section{Disciplinary Differences}

Few studies have examined how disciplinary differences influence the advising relationship and doctoral experience. Lovitts (2001) looked at advising differences between doctoral students in natural sciences and those in social sciences and humanities. She noted that doctoral students in social sciences and humanities did not receive the same type of academic and social support as their counterparts in the natural sciences. Golde (2005) noted that advising experiences were markedly different between students pursuing degrees in science disciplines and those in humanities fields: The former had a much more close-knitted advising experience and departmental support than the latter.

Faculty in physical and biological sciences often work in tandem with their advisees in a laboratory, which doubles as a central site of socialization (Jeong et al., 2019). Furthermore, in science and science-related fields, the student and the advisor often match during the admission process, giving them more time to build their relationship (Zhao et al., 2007). This relationship is further nurtured by the culture embedded within laboratory and research groups, which emphasize cooperation, a group-centered mindset, and regular faculty contact. Conversely, students in social science and humanities fields tend to pursue more solitary activities. These fields often assign students to an interim advisor, expecting that within two to three semesters a student will establish a relationship with a permanent advisor. While these students may enjoy more individual attention, it is not until they pass their qualifying exams that they work in much closer proximity with their permanent advisor. Therefore, the length of time available to build a relationship is severely curtailed for students in these disciplines (Barnes et al., 2010).

\section{Selection Criteria}

There are several factors that international graduate students consider when they select their advisor: advisor's reputation as a mentor and a researcher, their available funding, research area, personality, time-to-degree reputation, career prospects, career stage, and gender (Janer, 2017; Joy et al., 2015). Academic discipline also plays a role in how much weight is given to the characteristics mentioned above. In Zhao et al. (2007), doctoral students in science fields were less concerned with intellectual compatibility with their advisor and more concerned with pragmatic elements (i.e., access to funding and laboratory resources) than humanities students.

A prospective advisor's demographics are also important considerations for both domestic and international doctoral students. Ellis (2001) found that female and racial minority graduate students were more likely to consider a faculty advisor's race and gender over their research-related reputation. Labon (2013) posited that the importance of these selection criteria stemmed from the general 
lack of representation of minority faculty of color and female faculty across various academic disciplines. This lack of representation deprives students of connecting with faculty with whom they share an important attribute and who may be better positioned to understand student concerns and to extend support (Burt et al., 2018). Najjar (2015) supported Labon's conjecture by reporting that international doctoral students who selected an international advisor were more satisfied with their advisor and doctoral program.

\section{Differences in Advising Experiences for International Students}

Takashiro (2017) noted that international doctoral students tend to value their relationship with advisors even more than domestic students and express a greater preference for advisors who are involved in their lives. However, they are less likely to experience and develop such relationships. Roksa et al. (2018) found that most international doctoral students in their sample reported a rather formal advising relationship with their faculty advisor than a more personalized and caring relationship (Dericks et al., 2019). This is unfortunate since international students are less likely to be aware of and to have access to campus resources, and an involved faculty advisor could alleviate some of the distress that occurs as part of the doctoral experience (Roberts et al., 2018).

The extent and depth of the advising relationship is also complicated by race and racism within higher education. In relation to advising, international doctoral students have reported instances of racism, stereotyping, and hostility (Glass et al., 2015). However, the ability for many of these students to change advisors may not always be possible, especially among those who often rely on institutional funding to support their education and whose funding is tied to a specific faculty advisor's research project. International doctoral students who have continued in such toxic relationships have reported increases in stress, anxiety, disengagement, and depression (Kim, 2011; Rice et al., 2016).

\section{METHOD}

\section{Participants}

Twenty-one first-year international doctoral students attending a large research-intensive Southeastern university participated in this study, hailing from the following regions: Asia, Oceania, Africa, Latin and South America, and Europe. The sample consisted of 10 female and 11 male participants, most of whom were in their mid-to-late 20s; the average age was 27 years old. A slight majority of participants had previous educational experiences in the United States before starting their doctoral program, either as study abroad participants or as degree-seeking undergraduates. However, all but three students had stayed less than 5 years in the United States at the time of interview. Their academic disciplines were grouped into one of the following categories: humanities, social science, STEM, business, and education. While we asked participants to specify 
their native country during the interview process, we present only a regional identifier in Table 1 to protect their anonymity.

Table 1. Descriptive Statistics of the Sample

\begin{tabular}{lcc}
\hline Characteristics & $n$ & $\%$ \\
\hline Gender & 10 & \\
$\quad$ Female & 11 & $48 \%$ \\
$\quad$ Male & $52 \%$ \\
Region of origin & 13 & \\
$\quad$ Asia \& Oceania & 2 & $62 \%$ \\
Africa & 3 & $10 \%$ \\
Latin \& South America & 3 & $14 \%$ \\
$\quad$ Europe & 5 & $14 \%$ \\
Major discipline & 1 & \\
Humanities & 1 & $24 \%$ \\
Social Science & 11 & $5 \%$ \\
STEM & 4 & $19 \%$ \\
Business \& Education & & \\
Age & 7 & $33 \%$ \\
20-25 & 11 & $52 \%$ \\
$26-30$ & 2 & $10 \%$ \\
$31-35$ & 1 & $5 \%$ \\
$36+$ & & \\
Previous educational experiences in the US & 12 & $57 \%$ \\
Yes & 9 & $43 \%$ \\
No & & \\
\hline
\end{tabular}

\section{Research Team}

The research team was composed of four researchers: one Asian female faculty member, one non-Latino White female graduate student, one non-Latino White male graduate student, and one Black female postdoctoral student. The latter acted as the project's auditor and did not participate in all team meetings in order to offer an impartial opinion during the audit process. However, she was instrumental in guiding the remaining three researchers in consensual qualitative research (CQR) data collection and analysis (Hill et al., 1997). All team members had lengthy experiences in different international contexts and were purposefully recruited because of these experiences and perspectives that they could bring to the study. Before developing the interview protocol, all team members shared their personal biases and expectations that could skew data analysis, and continually revisited them throughout the research project to ensure data integrity.

\section{Interview Protocol}

This study is a subset of a larger qualitative study focused on understanding first-year international doctoral student experiences. Questions exploring advising 
experiences were created by the research team and developed by consulting the literature, engaging in informal conversation with international graduate students, and participating in ongoing discussion among the research team. The final interview protocol consisted of six questions (e.g., "Can you share with us what you consider to be the most important qualities for a faculty advisor?") and appropriate probing questions (e.g., "Describe how you do or don't feel supported by your advisor."). Participants completed a short demographic questionnaire prior to scheduling their interview, which collected data on their academic discipline, country of origin, and previous educational experiences in the United States. Other demographic and descriptive information were obtained during the course of the interview (e.g., type of faculty advisor, institutional funding, and partner/dependent status).

\section{Data Collection}

After securing Institutional Review Board approval, eligible participants were recruited via email sent via the International Scholar and Student Services office on the study campus and word of mouth. Data collection lasted from lateJanuary to May 2018. All interviews were audio-recorded and transcribed by the interviewer who conducted the interview; average interview time was approximately $60 \mathrm{~min}$. Data authenticity was ensured by allowing participants the option of reviewing their interview transcript to confirm that their words and meaning were accurately represented; if discrepancies arose, the original interviewer worked with the participant to revise the transcript.

\section{Data Analysis}

We utilized CQR methodology created by Hill et al. (1997) to guide our data analysis. Given our small sample size, CQR was most appropriate because it allows researchers to conduct in-depth analyses on a smaller number of cases and attain a deeper understanding of the experience. Following Hill's (2012) CQR standards, all analysis decisions were made by group consensus to ensure that no singular perspective skewed the analysis. After concluding the transcription, team members spent about 3 weeks independently analyzing the transcripts and creating prospective themes within Microsoft Word.

Then, the team reconvened and reviewed each member's list of themes, pointing out overlap and discrepancies in the data. Based on these conversations, a single domain list was created, and the team returned to their transcripts and coded anew based on the domain list. To produce coding stability, one research team member verified all coding for accuracy and collaborated exclusively with the independent auditor to review and correct any errors in the coding scheme and/or coding on each transcript. Following this stage, the research team engaged in cross-analysis (Hill, 2012) to jointly identify shared themes across the participants, which were then grouped into thematic domains. The domains were validated by another round of coding and checks by each team member. The 
auditor completed a final review and the feedback was addressed by the team members and integrated into the final analysis.

\section{RESULTS}

Data analysis produced the following four domains: (a) advisor-advisee matching; (b) frequency and method of meetings with an advisor; (c) content of advising conversations; and (d) satisfaction with advising. Identified domains were further broken down into categories that were assigned a frequency label of general, typical, or rare to capture the occurrence of the theme among the participants (Hill, 2012). Table 2 provides a summary of domains, categories, and frequencies.

Table 2: Summary of Domains, Categories, and Frequencies

\begin{tabular}{lcc}
\hline Domain & Frequency & $n$ \\
\hline Advisor-advisee matching & & \\
$\quad$ Pre-enrollment & Rare & 2 \\
Interim assignment & General & 17 \\
Postmatriculation & Rare & 3 \\
Frequency \& style of interaction & & \\
Group meetings & Rare & 2 \\
Individual meetings & General & 17 \\
Infrequent meetings & Typical & 10 \\
Content of advising conversations & & \\
Procedural elements & General & 19 \\
Personal \& career topics & Rare & 4 \\
Satisfaction with advising & & \\
Positive & General & 18 \\
Negative & Rare & 2 \\
Neutral & Typical & 12 \\
\hline
\end{tabular}

Note. $N=21$. General $=$ At least 17 respondents shared the same category; typical $=10-16$ respondents shared the same category; rare $=$ fewer than nine respondents shared the same category.

\section{Advisor-Advisee Matching}

This domain refers to the method of advisor matching the participant experienced in their program. Among our participants, we found three types of matching styles: (a) faculty advisor selected by the student before enrolling, (b) interim faculty advisor assigned by the department, and (c) a student currently in the process of seeking out a permanent advisor. Two participants who selected their faculty advisor had previous interactions with them at a conference or a field research site before applying to the university. 
Most participants, regardless of academic discipline, were assigned to an interim advisor, typically the Director of Graduate Studies (DGS) for the program. Given that all participants were first-year students, this is not unusual. However, these participants reported being unsure of how to approach the DGS and how to begin seeking a permanent advisor. And while participants assigned to an interim advisor generally reported a favorable relationship 1 year into their assignment, many were ready to find their permanent advisor. A male participant from Africa studying computer science framed it thusly, "I don't know this person now, but I need to get to know them and maybe this will become a real partnership." However, several participants with an interim advisor also indicated not being sure if the DGS advisor could become a permanent advisor and engaged with them sparingly as a result.

The last category encompasses participants who were in the process of seeking out a permanent advisor (moving away from their interim advisor), and all three participants were from STEM fields. These participants indicated that their study programs generally gave them two to three semesters to find a permanent advisor. They reported feeling stressed having to "speed date" faculty members in the length of time provided, especially as many of them were not yet sure of their research agenda and graduate school goals. Participants shared different tactics to interview prospective advisors. For example, a female participant from Asia studying biomedical sciences stated:

I have visited every professor in my department at least once so far. I have a list of questions I bring. If I've had class with them, I go back and review old class material, so that I can start a conversation based on that and then, maybe, the conversation won't be so bad.

Although others in this category were not as organized, they did have their own tactics to screen for possible advisors; for example, a male participant from Asia noticed that several faculty members from his department frequented the campus gym. He used that opportunity to befriend them and even learned how to play squash adding, "I had no clue what this sport is. But, I like to be active and they were there to teach me, so I did it." He emailed his interviewer a few weeks later and informed her that one of the squash-playing faculty members was now his permanent advisor.

\section{Meeting Frequency and Interaction Style Based on Academic Discipline}

This domain is defined by the frequency and method of advisor-advisee meetings, which we found varied based on academic discipline. Humanities and social science participants reported infrequent meetings with their faculty advisor, greater emphasis on scheduling a formal time for those meetings, and a greater frequency of conducting such meetings via email, in comparison to STEM participants. A Central European female participant studying in the social sciences added, "It's a bit hard to arrange these meetings because I wasn't quite sure who my advisor was. I mean, it's the DGS, but, for how long? It's hard to get on his schedule to talk about what comes next." The student's annoyance with 
scheduling was shared by several other humanities participants who also added that they felt "unimportant" in comparison with their older peers in the program whom they perceived as enjoying more direct and frequent advisor attention. Additionally, these participants also reported fewer informal gatherings amongst themselves at the departmental level indicating a more aloof atmosphere.

By way of comparison, participants majoring in STEM or in biomedical sciences reported a greater frequency of group meetings because these fields put greater emphasis on teamwork as part of laboratory work and their study curriculum (Zhao et al., 2007). For example, a male STEM participant from Southeast Asia stated, “...we have a group meeting every Monday and then there is a subgroup meeting. The subgroup meeting is an important one. We have to meet twice at least every month." Participants in this group also perceived that their advisors were available for individual consultation even though they did not always utilize the opportunity. They also reported greater occurrences of social hours built into laboratory time so that various faculty and students could mingle and engage in informal individual advising. A female participant from Southeast Asia studying biomedical sciences shared the following:

Our department has Cookie Hours every day from four to five, and we just go into our lobby and have cookies and coffee or tea. I like that I can look forward to this every day and it's easier to meet other people and to get to know faculty and ask questions.

Because STEM and biomedical science fields tend to be more collaborative in their work in contrast to humanities and social science fields, it is natural that these departments relied on social hours and group meeting formats to create a culture of support.

\section{Content of Advising Conversations Based on Matching Style}

This domain is defined by the types of conversations and topics participants engaged in with their faculty advisor and how these conversations differed based on their matching style. Perhaps unsurprisingly, most of our participants reported engaging in formal conversations about program requirements, timelines, and procedural matters, which are reminiscent of prescriptive advising. Since most of them were assigned to an interim advisor, there was also a general unawareness of how to engage with their advisor. A male participant from northern Africa studying in a STEM field explained, "I'm not sure what I can talk about with him. So, we just talk about classes. I don't know if he wants to know more about me." Other participants felt similarly, citing that they "didn't want to bother" the faculty advisor with their stories. When asked if their faculty advisor or department ever explained their advising philosophy and the types of conversations they could engage in, many indicated that they did not recall these topics. Providing such information and encouragement may be helpful to international students who come from cultures that emphasize hierarchy and deference to authority and who may see engagement in informal conversation without proper approval as impertinence. 
Among participants who selected their faculty advisor prior to commencing their programs, we found that they engaged in more holistic conversations that also included disclosure of personal and career information, which aligns with developmental advising principles. A female social sciences participant from Central Asia described the conversations with her advisor like this:

I had a lot of trouble getting the paperwork approved to come to the United States. I also had a baby right before I arrived and so I knew no one here, and [my] husband was delayed in getting approval for several months, so I had no one. I had to ask my advisor for help. I could not have done it otherwise. And you know, my advisor was great. She was flexible with me, she let me leave class early sometimes to get my baby. She always asked me how I was doing and if I needed help.

Participants who shared an important attribute with their advisor (i.e., country of origin or gender) also reported engaging in more personal conversations, supporting Labon's (2013) conclusion. A female business participant from Southeastern Europe remarked, "I really wanted her to be my advisor because we're from the same country and that worked out. I really rely on her, on everything, and let's say I try not to overload her, but I really rely on her." The fact that the participant shared the same language, gender, and country of origin as her advisor could have increased her confidence in her chosen field of study, and she may have also felt more valued and heard because they shared the same language.

Overall, very few participants engaged in career-oriented conversations with their advisors. Among those who did, they tended to be within STEM and biomedical science fields. The applied nature of their curriculum and the higher frequency of interactions with faculty, both formal and informal, may create a natural pocket for career-oriented conversations to occur. A female participant from Oceania studying biomedical sciences stated, "I see my laboratory faculty every day. Of course, we'd talk about career prospects after school. I need their sponsorship and endorsement to get into a postdoc, or when I begin my own lab." While some participants in humanities and social sciences could articulate their career goals during the interview process, many indicated that they did not discuss these goals with their advisor due to the infrequency of their advising meetings and perceived lack of support.

\section{Satisfaction with Advising}

This domain refers to the participants' satisfaction with their advising relationship: positive, negative, or neutral. Most participants expressed positive feelings and thoughts toward their faculty advisor and advising relationship, using descriptors like knowledgeable, warm, friendly, and caring. This is a notable finding since the majority of our participants were still being advised by an assigned interim advisor rather than by one they had preselected, which is contrary to the literature. For example, a female participant from Central Europe studying in the humanities field shared, "He's like my grandfather and he's very 
personable. I can ask him anything and he'll always give me an answer. If he sees me on campus, he will be the first to say hello." Many cited the novelty of being on a new campus and having new experiences as enough to outweigh some negative aspects like being homesick, adjusting to new cuisine, and having to make new friends.

Even participants who had infrequent conversations with their advisors reported finding their way around their department and campus by relying on new or existing social networks, asking departmental administrative assistants, and searching the internet. They indicated feeling more in control and that they had become resourceful. A female participant from Central Europe studying social sciences added, "I'll email anyone that I can think of. People will reply, even if I shouldn't be emailing them, and they will point me in the right direction." While we applaud this type of resourcefulness as a marker of self-sufficiency, it is also a warning sign that students do not have readily accessible faculty who may be a more accurate fount of knowledge in comparison with informal friendship networks and the internet.

Participants who indicated negative feelings about their advisor usually remarked that they felt that their advisor did not have time for them and that their attempts to create a relationship were not encouraged. A female participant from South America studying in the humanities field added that she felt like her advisor considered her a "nuisance" because he rarely replied to her emails or offered his time to meet individually with her. She indicated finding greater support from the departmental administrative assistant. Similarly, a female participant from Asia studying in the social sciences recalled how repeated in-class slights by her advisor made her doubt her ability to be successful in her program. She explained that her advisor often called her research topic "meaningless" adding that "I feel he's trying to push me to think deeper, but the way he pushes me, it's really discouraging me... because his attitude to other White students is not the same as his attitude to me." Both participants felt that their educational experience and professional goals were jeopardized because their advisors did not offer help, leaving them unsure about if they should continue their studies at this study site.

Participants in the neutral category did not have clearly defined positive or negative opinion toward their advising relationship. Rather, they seemed content with the transactional nature of their advising relationship and were fine with having their advisor be a more distant figure in their lives. A male participant from Southeast Asia studying in a STEM discipline stated, "I know she's there and I can ask her what I need, but I don't see a need and so I don't." Others similarly remarked that they wished to keep a clear demarcation between school and personal lives, choosing not to engage with peers and faculty at the same frequency as others. Perhaps these students did not wish to share their deeper feelings with the interviewers, were still processing their first year, or did not have a deeper emotional connection to their graduate programs. But, these types of students may be more at risk of leaving because they are not being well-integrated in their programs. 


\section{DISCUSSION}

Overall, participants in STEM and biomedical science fields reported more frequent group interactions with their faculty advisor due to the curricular configuration that relies heavily on laboratory and group work, bringing them in more routine contact with one another. These participants were also likelier to engage in career-oriented conversations with their faculty advisor, which signals a more holistic approach to graduate student development. The relative short duration of these graduate programs and their direct connections to industry may create a more natural opening for these types of conversations. Our findings controvert those of Noy and Ray (2012) who suggested that students in physical and biological sciences receive less attention and support than students in humanities and social science fields. It could be due to the recent emphasis that STEM fields have placed on improving their retention by modifying their culture and student support systems (Eshani et al., 2017).

Participants in the humanities and social science fields reported infrequent interactions, a harder time getting in touch with their faculty advisor, and a greater emphasis on formal meetings compared with participants in STEM fields. These students tended to have conversations with their faculty advisors about procedural requirements. While eager to engage with their advisors, many felt that they were overlooked in favor of older peers who were further along in the program.

\section{Implications and Recommendations}

Our findings suggest that baseline expectations for faculty advising need to be created and sufficiently articulated to both students and faculty advisors. Some U.S. schools have already invested in innovative ways to support and engage their doctoral students. For example, University of Pittsburgh has issued guidance to all graduate departments on what are considered elements of good academic advising (University of Pittsburgh, n.d.). Such guidance includes specific responsibilities of faculty and academic units, including providing accurate and written information regarding program requirements as well as after-graduation employment opportunities and checking students' progress and performance on a regular basis. Student responsibilities are also stipulated, like alerting advisors to uncertainty about program requirements or progress. We also suggest the use of an advising syllabus as utilized by various colleges at George Washington University to clearly communicate advising expectations to both faculty and doctoral students (George Washington University, n.d.). Lastly, we recommend institutions provide resources and workshops for faculty who teach, advise, and work with international students. For instance, Carnegie Mellon University provides online handbooks that share best practices for faculty and advisors working with international students (Eberly Center for Teaching Excellence, \& Intercultural Communication Center, n.d.). These resources would help faculty become knowledgeable of different cultures and more understanding of international students. 
We also recommend weaving advising opportunities into formal orientations, program curricula, and department social events. While our participants indicated attending orientations offered by their department, college, and the university's international center, many of these orientations were simply social in nature rather than substantive in content pertinent for first-year doctoral students. To alleviate the deficiency of such orientations, we recommend mandating a seminar class for all first-year graduate students and requiring them to conduct interviews with all department faculty members as a course assignment, which can be a great way to orient students to the department and to meet with faculty members. Creating an informal space (e.g., snack hours, a kitchen with coffee and a microwave, etc.) that brings faculty and students into routine contact is another recommendation, which seemed to work well for students in our sample.

Examined through the lens of developmental advising, many faculty advisors in this study engaged in routine and prescriptive advising that is far more transactional in nature rather than developing a deeper and holistic relationship with their advisees. Due to the interim assignment of most faculty advisors, it is not unusual that they would be more focused on the immediate needs of the participants rather than investing time in developing a long-term relationship. However, even though their advising obligation may be short term, interim advisors can play an important role in orienting their advisees to departmental expectations and culture. We suggest that interim faculty advisors reach out to advisees, set up regular meetings, and check up on them during major academic calendar milestones to ensure they understand appropriate departmental policies and timelines and to build more meaningful and genuine relationships with them. This way, when students are permanently matched to a faculty advisor, they enter into that new relationship prepared with more information and confidence to articulate their personal and academic goals.

For future research, we call for more empirical studies that examine advising experiences of international graduate students, and how advising influences their success in graduate school. Our study focused on their matching process and advising experiences in their first year, but it would be interesting to explore how the relationship between advisor and advisee develops and how it influences outcomes at the dissertation and job market stages. We also encourage researchers to examine faculty perspectives on graduate advising - in particular their experiences and expectations for advising international graduate students - so that we can have a better understanding of what faculty know about advising, their experiences with advising this population, and where they need assistance in improving their advising.

From a practical standpoint, faculty advisors and DGSs should consider conducting yearly advising evaluations to identify areas for improvement and success. Graduate students could also complete these evaluations anonymously so that both perspectives can be considered. This would signal to faculty and students that advising is taken seriously by the department. Additionally, departments should consider ways to reward advising excellence by publicly recognizing outstanding faculty advisors or by weighing advising excellence more in tenure and promotion decisions. After all, effective advising positively 
contributes to student success and to faculty development (Ruud et al., 2018). Lastly, to ensure that students get sufficient attention from their advisors and have good advising experiences, departments should consider limiting the number of students a faculty member may advise at any given time (e.g., Noble, 2000), or the type of faculty who could serve as advisor, like Stanford University (Flaherty, 2018).

\section{Limitations}

There are several limitations to this study, with the primary one being our small sample size given the total international graduate student enrollment at the study site. Additionally, this study is situated at a large research university in the Southeast. Therefore, students' advising and overall first-year experiences may differ based on geographic region, selectivity, or institutional size, which limits generalizability of the study's results to the entire international doctoral student population in the United States. Lastly, this study only interviewed students and lacks faculty advisors' perspectives and experiences. Future studies can incorporate both student and faculty narratives and delve deeper into how these two groups understand the nature and purpose of the advising relationship.

\section{CONCLUSION}

International doctoral students encounter plenty of challenges at the start of their academic journey in the United States. Effective advising can help these students successfully adjust to the transition and achieve their goals in graduate school. In this study, we described how international doctoral students' advising experiences varied across academic disciplines and advisor-advisee pairing methods. We suggested a few example practices that could clarify advising expectations and increase contact between advisors and advisees, both of which could improve the overall advising experience. International students are critical assets to U.S. campuses both intellectually and culturally. Ensuring their success can benefit both international and domestic students, as well as faculty. We hope that this research provides a way to help international students adjust to and succeed in graduate school in the United States.

\section{REFERENCES}

Arthur, N. (2017). Supporting international students through strengthening their social resources. Studies in Higher Education, 42(5), 887-894. https://doi.org/10.1080/03075079.2017.1293876

Barnes, B. J., Williams, E. A., \& Archer, S. A. (2010). Characteristics that matter most: Doctoral students' perceptions of positive and negative advisor attributes. NACADA Journal, 30(1), 34-46. https://doi.org/10.12930/02719517-30.1.34 
Boyce, B. A., Napper-Owen, G., Lund, J. L., \& Almarode, D. (2019). Doctoral students' perspectives on their advisors. Quest, 71(3), 321-332. https://doi.org/10.1080/00336297.2019.1618076

Burt, B. A., Williams, K. L., \& Smith, W. A. (2018). Into the storm: Ecological and sociological impediments to Black males' persistence in engineering graduate programs. American Education Research Journal, 55(5), 965-1006. https://doi.org/10.3102/0002831218763587

Chen, B., Tabassum, H., \& Saeed, M. A. (2019). International Muslim students: Challenges and practical suggestions to accommodate their needs on campus. Journal of International Students, 9(4), 933-953. https://doi.org/10.32674/jis.v9i3.753

Crookston, B. B. (1972). A developmental view of academic advising as teaching. Journal of College Student Personnel, 13(1), 12-17.

Curtin, N., Stewart, A. J., \& Ostrove, J. M. (2013). Fostering academic selfconcept: Advisor support and sense of belonging among international and domestic graduate students. American Educational Research Journal, 50(1), 108-137. https://doi.org/10.3102/0002831212446662

Dericks, G., Thompson, E., Roberts, M., \& Phua, F. (2019). Determinants of PhD student satisfaction: The roles of supervisor, department, and peer qualities. Assessment \& Evaluation in Higher Education, 44(7), 1053-1068. https://doi.org/10.1080/02602938.2019.1570484

Eberly Center for Teaching Excellence, \& Intercultural Communication Center. (n.d.). Recognizing and addressing cultural variations in the classroom. Carnegie Mellon University. https://doi.org/https://www.cmu.edu/teaching/resources/PublicationsArchiv es/InternalReports/culturalvariations.pdf

Ellis, E. M. (2001). The impact of race and gender on graduate school socialization, satisfaction with doctoral student, and commitment to degree completion. The Western Journal of Black Studies, 25, 30-45.

Eshani, G. L., Skaza, H., Marti, E., Schrader, P. G., \& Orgill, M. (2017). Perceptions of student recruitment and retention in STEM fields. European Journal of STEM Education, 2(1), 1-11. https://doi.org/10.20897/esteme.201702

Flaherty, C. (2018, April 16). Graduate advising matters. Inside Higher Education. https://www.insidehighered.com/news/2018/04/16/stanfordseeks-improve-graduate-student-advising

George Washington University. (n.d.) Advising syllabus for graduate students. Elliot School of International Affairs. https://lliott.gwu.edu/sites/g/files/zaxdzs2141/f/downloads/acad/advising/f orms/Advising\%20Syllabus\%20for\%20Graduate\%20Students_Sp18.pdf

Glass, C. R., Kociolek, E., Wongtrirat, R., Lynch, R. J., \& Cong, S. (2015). Uneven experiences: The impact of student-faculty interactions on international students' sense of belonging. Journal of International Students, 5(4), 353-367. 
Golde, C. M. (2005). The role of the department and discipline in doctoral student attrition: Lessons from four departments. The Journal of Higher Education, 76(6), 669-700. https://doi.org/10.1080/00221546.2005.11772304

Harris, T. A. (2018). Prescriptive vs. developmental: Academic advising at a historically black university in South Carolina. NACADA Journal, 38(1), 3646. https://doi.org/10.12930/NACADA-15-010

Heng, T. T. (2016). Different is not deficient: Contradicting stereotypes of Chinese international students in US higher education. Studies in Higher Education, 43(1), 22-36. https://doi.org/10.1080/03075079.2016.1152466

Hill, C. E. (2012). Consensual qualitative research: Practical resource for investigating social science phenomena. American Psychological Association.

Hill, C. E., Thompson, B. J., \& Williams, E. N. (1997). A guide to conducting consensual qualitative research. The Counseling Psychologist, 25(4), 207217. https://doi.org/10.1177/0011000097254001

Hunter, K. H., \& Devine, K. (2016). Doctoral students' emotional exhaustion and intentions to leave academia. International Journal of Doctoral Studies, 11, 35-61. http://ijds.org/Volume11/IJDSv11p035-061Hunter2198.pdf

Janer, S. J. (2017). Graduate students' satisfaction on the thesis advising practices. Asia Pacific Journal of Multidisciplinary Research, 5(1), 23-30.

Jeong, S., Blaney, J. M., \& Feldon, D. F. (2019). Identifying faculty and peer interaction patterns of first-year biology doctoral students: A latent class analysis. CBE - Life Sciences Education, 18(4), 1-13. https://doi.org/10.1187/cbe.19-05-0089

Joy, S., Liang, X., Bilimoria, D., \& Perry, S. (2015). Doctoral advisor-advisee pairing in STEM fields: Selection criteria and impact of faculty, student and departmental factors. International Journal of Doctoral Studies, 10, 343363. http://ijds.org/Volume10/IJDSv10p343-363Joy0711.pdf

Kim, J. (2011). The birth of academic subalterns: How do foreign students embody the global hegemony of American universities? Journal of Studies in International Education, 16, 455-476. https://doi.org/10.1177/1028315311407510

Knox, S., Sokol, J. T., Inman, A. G., Schlosser, L. Z., Nilsson, J., \& Wang, Y.W. (2013). International advisees' perspectives on the advising relationship in counseling psychology doctoral programs. International Perspectives in Psychology: Research, Practice, Consultation, 2(1), 45-61. https://doi.org/10.1037/ipp0000001

Kong, X., Chakraverty, D., Jeffe, D. B., Andriole, D. A., Wathington, H. D., \& Tai, R. H. (2013). How do interaction experiences influence doctoral students academic pursuits in biomedical research? Bulletin of Science, Technology \& Society, 33(3-4), 76-84. https://doi.org/10.1177/0270467613516754

Labon, T. N. (2013). The effects of race and gender on the satisfaction levels of entering and advanced level doctoral students [Doctoral dissertation, University of Southern Mississippi]. https://aquila.usm.edu/dissertations/432

Litalien, D., \& Guay, F. (2015). Dropout intentions in $\mathrm{PhD}$ studies: A comprehensive model based on interpersonal relationships and motivational 
resources. Contemporary Educational Psychology, 41, 218-231. https://doi.org/10.1016/j.cedpsych.2015.03.004

Lovitts, B. E. (2001). Leaving the ivory tower: The causes and consequences of departure from doctoral study. Rowman and Littlefield.

McWilliams, A. E., \& Beam, L. R. (2013). Advising, counseling, coaching, and mentoring: Models of developmental relationships in higher education. Scholarship on Academic Advising, 15, 7-16. https://doi.org/10.26209/MJ1561280

Najjar, K. (2015). International doctoral students, their advising relationships and adaptation experiences: A qualitative study [Doctoral dissertation, University of Nebraska-Lincoln]. https://digitalcommons.unl.edu/cehsedaddiss/255

Ng, K., Lau, J., \& Crisp, G. (2018). Advising and mentoring in counselor education. In J. E. Atieno-Okech \& D. J. Rubel (Eds.), Counselor education in the 21 $1^{\text {st }}$ Century: Issues and experiences (pp. 53-72). American Counseling Association.

Noble, J. H. (2000). Cherchez l'argent: A contribution to the debate about class size, student-faculty ratios, and use of adjunct faculty. Journal of Social Work Education, 36(1), 89-

102. https://doi.org/10.1080/10437797.2000.10778992

Noy, S., \& Ray, R. (2012). Graduate students' perceptions of their advisers: Is there systematic disadvantage in mentorships? The Journal of Higher Education, 83(6), 876-914. https://doi.org/10.1080/00221546.2012.11777273

Omar, F., Mahone, J. P., Ngobia, J., \& FitzSimons, J. (2016). Building rapport between international graduate students and their faculty advisors: Crosscultural mentoring relationships at the University of Guelph. The Canadian Journal for the Scholarship of Teaching and Learning, 7(2), 1-17. http://dx.doi.org/10.5206/cjsotl-rcacea.2016.2.8

O'Meara, K., Knudsen, K., \& Jones, J. (2013). The role of emotional competencies in faculty-doctoral student relationships. Review of Higher Education: Journal of the Association for the Study of Higher Education, 36(3), 315-347. https://doi.org/10.1353/rhe.2013.0021

Rice, K. G., Choi, C. C., Zhang, Y., Villegas, J., Ye, H. J., Anderson, D., Nesic, A., \& Bigler, M. (2009). International student perspectives on graduate advising relationships. Journal of Counseling Psychology, 56(3), 376391. https://doi.org/10.1037/a0015905

Rice, K. G., Suh, H., Yang, X., Choe, E., \& Davis, D. E. (2016). The advising alliance for international and domestic graduate students: Measurement invariance and implications for academic stress. Journal of Counseling Psychology, 63(3), 331-342. http://dx.doi.org/10.1037/cou0000141

Roberts, P. A., Dunworth, K., \& Boldy, D. (2018). Towards a reframing of student support: A case study approach. Higher Education, 75(3), 19-33. https://doi.org/10.1006/s10734-017-0127-z

Roksa, J., Feldon, D. F., \& Maher, M. (2018). First-generation students in pursuit of the $\mathrm{PhD}$ : Comparing socialization experiences and outcomes to 
continuing-generation peers. The Journal of Higher Education, 89(5), 728752. https://doi.org/10.1080/00221546.2018.1435134

Ruud, C. M., Saclarides, E. S., George-Jackson, C. E., \& Lubienski, S. T. (2018). Tipping points: Doctoral students and consideration of departure. Journal of College Student Retention: Research, Theory \& Practice, 20(3), 286-307. https://doi.org/10.1177/1521025116666082

Shapiro, S., Farrelly, R., \& Tomaš, Z. (2014). Fostering international student success in higher education. TASOL Press.

Takashiro, N. (2017). Asian international graduate students' extrinsic motivation to pursue degrees. Psychological Thought, 10(1), 178-189. http://dx.doi.org/10.5964/psyct.v10i1.199

University of Pittsburgh. (n.d.). Elements of good academic advising. https://www.provost.pitt.edu/students/graduate-studies/elements-goodacademic-advising

Wang, R., \& Lorenz, A. B. (2018). International student engagement: An exploration of student and faculty perceptions. Journal of International Students, 8(2), 1002-1033. https://doi.org/10.5281/zenodo.1250402

Zhao, C., Golde, C. M., \& McKormick, A. C. (2007). More than a signature: How advisor choice and advisor behaviour affect doctoral student satisfaction. Journal of Further and Higher Education, 31(3), 263-281. https://doi.org/10.1080/03098770701424983

Zong, J., \& Batalova, J. (2018). International students in the United States. Migration

Policy

Institute.

https://www.migrationpolicy.org/article/international-students-united-states

NINA MARIJANOVIĆ is a doctoral candidate in the Educational Policy Studies and Evaluation Department at the University of Kentucky. Her major research interests lie in the area of faculty socialization, training, and retention, with special focus on higher education institutions and policy in the Western Balkans. Email: nina.marijanovic@uky.edu

JUNGMIN LEE is an Assistant Professor in the Educational Policy Studies and Evaluation Department at the University of Kentucky. Her major research interests lie in the area of higher education policy that promotes college access and success. Email: jungmin.lee@uky.edu

THOMAS W. TEAGUE, JR. is a doctoral candidate in the Educational Policy Studies and Evaluation Department at the University of Kentucky. His major research interests lie in the area of global student mobility, spatiality, and organizational issues impacting international student support. Email: thomas.teague@uky.edu

SHERYL F. MEANS is a postdoctoral fellow in Africana Studies at University of New Mexico. Her major interests lie in the area of Afro-Latin America, racial identity formation, and comparative education studies. Email: sfmeans@unm.edu 